\title{
LA UTILIZACIÓN DEL CONCEPTO DE $p H$ EN LA PUBLICIDAD Y SU RELACIÓN CON LAS IDEAS QUE MANEJAN LOS ALUMNOS: APLICACIONES EN EL AULA
}

\author{
JIMÉNEZ LISO, MARÍA RUT' ${ }^{1}$, ME MANUEL TORRES, ESTEBAN ${ }^{1}$, GONZÁLEZ \\ GARCÍA, FRANCISCO ${ }^{1}$ y SALINAS LÓPEZ, FRANCISCO ${ }^{2}$ \\ ${ }^{1}$ Departamento de Didáctica de las Ciencias Experimentales. Facultad de Ciencias de la Educación. \\ Universidad de Granada. Campus de Cartuja. 18071 Granada \\ ${ }^{2}$ Departamento de Química Analítica. Facultad de Ciencias. Universidad de Extremadura. \\ Av. de Elvas, s/n. 06071 Badajoz
}

\begin{abstract}
SUMMARY
The broadcast on TV of some commercials where the value of the $\mathrm{pH}$ in the advertised products was presented as beneficial, prompted us to study them to analyse the ideas related with the acids and bases that they have. Here, we also seek possible coincidences with the ideas that students sustain. We also present a sequence of classroom activities to use commercials to work the concepts of $\mathrm{pH}$ and neutralization therein involved.
\end{abstract}

\section{INTRODUCCIÓN}

La publicidad, independientemente de las distintas actitudes hacia ella, es un elemento comunicativo con el que nuestros estudiantes comparten buena parte de su tiempo (Arconada, 1994). Hoy no es necesario tener que justificar su análisis y estudio como una de las actividades de la enseñanza formal. La omnipresencia social del mundo de la imagen y de la publicidad han erigido estos elementos en uno de los mayores diferenciadores entre el aula y el mundo externo a ella (Cabero, 1998).

Sin olvidarnos del contexto curricular en que nos situamos, la experiencia presentada afecta a la necesidad de utilizar la publicidad como herramienta didáctica en los procesos específicos de enseñanza-aprendizaje (Muñoz, 1995); necesidad que surge de la configuración actual de la sociedad en la que los medios de comunicación social y las nuevas tecnologías han puesto inmensas cantidades de información a disposición de casi todos. Indudablemente la publicidad es uno de los medios de comunica- ción social más influyente. Como elemento de nuestra cultura de masas, cultura del espectáculo y del comunicador anónimo (Morín, 1984), la publicidad debe ser utilizada como recurso en todas las aulas y en todas las áreas de conocimiento.

El elevado consumo que realizan nuestros jóvenes de la televisión y otros medios de comunicación basados en la imagen y la estética publicitarios convierten estos medios en un agente informal de educación de gran relevancia (Trilla, 1993). Lucas (1983) indica que la mayor parte de la información relacionada con conceptos científicos de los medios es sensacionalista o colorista aunque reconoce que se ha investigado poco sobre cómo los espectadores interiorizan las informaciones recibidas. La mayoría de las investigaciones sobre la publicidad en el aula provienen del área de la didáctica de la lengua y de las ciencias sociales (Román, Barroso y Domene, 1998). Por lo anteriormente comentado, 
consideramos que el mundo de la publicidad puede actuar como una fuente social para las concepciones con las que los alumnos acceden a las aulas.

Las concepciones socialmente inducidas, según la terminología de Pozo y otros (1991), más estudiadas son las que se deben al efecto del lenguaje y a las formadas por lo que la psicología social denomina representaciones sociales (Solomon, 1987).

El estudio del origen de las ideas o concepciones de los alumnos debe ser un elemento fundamental en el momento de organizar el currículo (Pozo et al., 1990, 1991). Al estudiar las ideas que manejan los alumnos universitarios sobre los conceptos relacionados con los ácidos y las bases (Jiménez, 2000), encontramos coincidencias entre éstas y las que aparecían en varios mensajes publicitarios. Los conceptos como ácido, base, acidez o basicidad son términos comunes y utilizados por la mayoría de las personas en la vida ordinaria. Sin embargo, en los currículos oficiales, el estudio de las reacciones ácido-base no aparecen hasta el segundo ciclo de la educación secundaria (MEC, 1991) y la referencia a las reacciones de transferencia de protones se contemplan en el segundo curso de bachillerato (MEC, 1992a, 1992b; De Manuel, 1997).

Puede discutirse el momento más adecuado para introducir en el currículo los conceptos de ácido-base, pero es indudable que los alumnos conocen y se enfrentan desde muy temprana edad con estos términos (lluvia ácida, caramelos ácidos, acidez de estómago, etc.); es más, la publicidad de diversos artículos no sólo recoge estos términos, sino que incluso utiliza conceptos específicos de la química como el pH y la neutralización.

El uso de conceptos científicos específicos por parte de los mensajes publicitarios abre un campo de trabajo sobre el origen social de ciertas concepciones de nuestros alumnos de ciencias. Mostramos aquí que algunas de las ideas que poseen los alumnos de secundaria y universidad sobre los procesos ácido-base pueden tener su origen o su refuerzo en la publicidad. Presentamos una secuencia de actividades del aula para trabajar con los conceptos relacionados con los ácidos y con las bases, aprovechando los propios mensajes publicitarios, estableciendo con ello un vínculo entre la publicidad y la didáctica de la ciencia.

\section{CONCEPCIONES DE LOS ALUMNOS DE SECUNDARIA Y UNIVERSIDAD}

Antes de comenzar con las ideas que los alumnos manejan referidos a la escala del $\mathrm{pH}$, queremos exponer brevemente qué es lo que establecen los científicos sobre los conceptos de $\mathrm{pH}$ y de neutralización.

En primer lugar, Sörensen, en 1909, expresó la concentración de iones $\mathrm{H}_{3} \mathrm{O}^{+}$en función de las potencias de 10 con exponente negativo y con el fin de reducir la escala de variación, definió el $\mathrm{pH}=-\log \left[\mathrm{H}_{3} \mathrm{O}^{+}\right](\mathrm{pOH}=$ $\left.-\log \left[\mathrm{OH}^{-}\right]\right)$. El pH es, por tanto, una magnitud cuantitativa, un valor numérico; es decir, las disoluciones no tienen $\mathrm{pH}$ ácidos, básicos o neutros sino que las disoluciones con valores del $\mathrm{pH}>7$ son básicas, las que tienen valores del $\mathrm{pH}<7$ son ácidas y para una disolución neutra o para el agua pura, a $25^{\circ} \mathrm{C}$, el $\mathrm{pH}=7$. De forma similar se suele presentar este concepto a los alumnos de secundaria. En segundo lugar, la Real Academia de las Ciencias Exactas, Físicas y Naturales (1996) define neutralización como «la adición de una disolución ácida a otra alcalina o viceversa hasta que la concentración de iones hidrógeno sea igual a la de iones hidroxilo, es decir, hasta alcanzar un $\mathrm{pH}=7$ ». Sin embargo, como ya hemos comentado (De Manuel, Jiménez y Salinas, 1999), hay que tener en cuenta que el término neutralización se utiliza tanto para las reacciones en las que el $\mathrm{pH}$ final es igual a 7 como para las reacciones estequiométricas (cuyo valor del $\mathrm{pH}$ puede ser distinto de 7) y también para denominar cualquier reacción ácido-base. Esta polisemia provoca confusiones en los alumnos, sobre todo en los procesos de valoración ácido-base, ya que muchos consideran que, en el punto de equivalencia, la disolución siempre es neutra $(\mathrm{pH}=7)$, independientemente de la fuerza de los ácidos y de las bases que reaccionen (De la Guardia et al., 1985; Vidyapati y Seethramappa, 1995). De este modo, Zoller (1990) destaca que muchos alumnos universitarios de $1^{\circ}$ de química general afirman que toda reacción ácidobase estequiométrica produce una disolución neutra aunque se trate de un ácido fuerte con una base débil. Según afirma Bárcenas (1997), algunos alumnos de secundaria identifican proceso ácido-base con reacción de neutralización.

Como indicábamos en una revisión bibliográfica presentada en un trabajo previo (De Manuel, Jiménez y Salinas, 1998), encontramos investigaciones que ponían de manifiesto que existe desconexión entre los fenómenos cotidianos y los conceptos que se aplican en el aula, como, por ejemplo, el hecho que señala Cros (1986 y 1988) de que los alumnos de todos los niveles tengan dificultades a la hora de clasificar como ácido o como básico productos comunes como café, leche o lejía, lo que pone de manifiesto que estos alumnos no aplican los conceptos de acidez a productos tan habituales en los hogares.

En diversas proporciones, los alumnos relacionan el $\mathrm{pH}$ de una disolución exclusivamente con la fuerza, con la concentración o con la intensidad de la reacción química (Zoller, 1990). Muchos alumnos de los primeros cursos de universidad sólo beberían disoluciones neutras (Cros, 1986 y 1988). Borsese (1992) comenta la importancia de utilizar correctamente el lenguaje y el significado de las palabras para ser rigurosos y precisos cuando nos refiramos a los conceptos de química en el caso concreto de la fuerza de los ácidos. En este sentido, Ross y Munby (1991) ponen de manifiesto que los alumnos de secundaria manifiestan que todos los ácidos son fuertes, poderosos y venenosos, y todas las sustancias que queman también son ácidas. 


\section{Metodología de la investigación}

En un trabajo más amplio que el que se recoge en estas páginas, desarrollado por nosotros (Jiménez, 2000), pretendemos realizar un seguimiento, a lo largo de los diferentes niveles educativos, con el fin de detectar cuáles son las dificultades que encuentran y los requisitos previos que deben reunir los alumnos a los que va destinada la materia que se les propone para su estudio así como elaborar secuencias de aprendizaje que se acomoden a los niveles de desarrollo cognoscitivo de los alumnos de las distintas etapas educativas.

El tema elegido (ácidos y bases) es susceptible de estar tan presente en los diferentes niveles educativos, que puede ser abordado desde perspectivas muy diversas: dificultades de enseñanza que encuentran los profesores de cada nivel educativo, contenidos actitudinales relacionados con el tema o, incluso, desde el punto de vista de la evaluación, por ejemplo, como oportunidad para el aprendizaje (Tamir, 1998). En nuestro trabajo previo (Jiménez, 2000) hemos explorado los procesos habituales de resolución de problemas, la utilización de las teorías ácido-base para debatir sobre la imagen de la ciencia que tienen los universitarios, así como la utilización de nuevas tecnologías en el aula con el objeto de utilizarlas como herramientas de mejora del aprendizaje de los contenidos implicados. En la presente publicación centraremos nuestra atención sobre una investigación más concreta y complementaria acerca del análisis de las ideas que destacan algunos mensajes publicitarios que hacen referencia al $\mathrm{pH}$ y a la neutralización como cualidades beneficiosas. Queremos relacionar las ideas destacadas por los anuncios con las concepciones de los alumnos universitarios para establecer unas bases que nos permitan elaborar una propuesta concreta que facilite el aprendizaje de los contenidos implicados, para lo cual utilizaremos el análisis de la publicidad como recurso didáctico.

La mayoría de los métodos utilizados en ese trabajo más amplio (análisis histórico-crítico, análisis de contenidos y de textos) se centran en la materia con el objeto de responder a ciertas preguntas como: ¿qué se ha enseñado? o ¿qué se enseña actualmente? La resolución de estas cuestiones, gracias al estudio histórico, permite aprender del pasado e identificar los obstáculos epistemológicos, así como el estudio de los textos y de los contenidos actuales ayuda a caracterizar el currículo actual y a detectar los posibles sesgos que se encuentran en él.

Para el estudio empírico de las concepciones de los alumnos diseñamos una prueba semiabierta (de opción múltiple, en la que se pedía que se justificara la elección) para diagnosticar conceptos relacionados con los ácidos y las bases en alumnos universitarios de todos los cursos $(\mathrm{N}=450)$, preferentemente de la licenciatura de químicas. En dicha prueba diseñamos un ítem para comprobar qué bebidas tomarían según el valor del $\mathrm{pH}$ que posean, obteniendo los siguientes resultados: a) el $44 \%$ de ellos sólo beberían disoluciones con valores del $\mathrm{pH}$ comprendidos entre 6 y $8 ; b$ ) el $24 \%$ considera que sólo pueden tener un valor del $\mathrm{pH}=7$ o pequeñas variaciones; $c$ ) tan sólo el $7 \%$ de los alumnos bebería sustancias ácidas con valores muy diferentes de 7, por ejemplo, $\mathrm{pH}=2,5$ (que es aproximadamente el $\mathrm{pH}$ de algunos refrescos).

$\mathrm{Al}$ analizar las justificaciones realizadas por los alumnos encontramos algunas respuestas de unos alumnos en las que se indicaba que hay que ingerir sustancias con unos valores del $\mathrm{pH}$ 6-8 para que no se produzca ninguna reacción ácido-base. Concretamente podemos señalar la respuesta de un alumno de $4^{\circ}$ curso en la que se señala esta idea: «[...] lo que hay que ingerir ha de ser entre 6-8 para que no se produzca reacción ácido-base». En esta respuesta se trasluce la idea observada en otras muchas, de que neutro parece significar «poco reactivo» o como se manifiesta en otros ítems de esta prueba, que neutro parece indicar «sin carácter ácido-base» en cualquier circunstancia. Probablemente nos encontramos con otro ejemplo de interferencia del lenguaje cotidiano en el lenguaje científico, un origen social de las concepciones previas muy común.

Un gran número de alumnos eligió las opciones que ponen de manifiesto que sólo se pueden beber disoluciones con valores del $\mathrm{pH}=7$ o próximos, y a la vez hicieron referencia a los problemas que los ácidos y las bases pueden provocar en el organismo. En muchas de sus respuestas citan los valores del $\mathrm{pH}$ del organismo y los posibles problemas para él. En estas justificiaciones existe una tendencia a relacionar lo neutro con loinocuo, «podemos tomar bebidas neutras porque no hacen daño», por ejemplo. Según este razonamiento, cuanto más nos alejemos del $\mathrm{pH}=7$, más riesgo para el organismo, ya que se producirían reacciones dañinas para órganos y tejidos (esófago, garganta, quemaduras en el aparato digestivo, úlceras, etc.). Un alumno del primer curso universitario afirma que un $\mathrm{pH}=7$ puede ocasionar la muerte. Esta confusión sobre el daño que las sustancias con un valor del $\mathrm{pH}=7$ pueden producir ha sido detectada por Nakhleh y Krajcik (1994), quienes señalan que los alumnos de secundaria confunden la fuerza de los ácidos con el «daño», «dolor» y con la reactividad. Entre las respuestas encontradas por nosotros también hay afirmaciones como: «[...] la ingestión de ácidos es necesaria para que no afecte a la piel, todos somos $\mathrm{pH}=5,5 \ldots$ variaciones bruscas de $\mathrm{pH}$ producen daño en los tejidos» (Jiménez, 2000).

Sólo el 7\% de los alumnos respondió que se podían ingerir disoluciones ácidas con valores del $\mathrm{pH}$ bastante diferente de 7. De estos alumnos, algunos aludían al $\mathrm{pH}$ del organismo, otros a problemas para el organismo y otros a la fuerza de los ácidos y de las bases. Sin embargo, los que mostraron mayor firmeza en su elección fueron los que hicieron referencia al $\mathrm{pH}$ de algunos alimentos habituales. Aunque las justificaciones de este tipo son muy escasas, en ellas parece estar la clave de una correcta aplicación de los conceptos, aprendidos en el aula, a la vida cotidiana.

Los alumnos que reconocen que se pueden ingerir alimentos con un $\mathrm{pH} \sim 2,5$ tal vez se basen en el conocimiento de que en el estómago hay una sustancia tan ácida como el $\mathrm{HCl}$. 
Sin embargo, esta correspondencia no es unívoca, es decir, no basta con que los alumnos aprendan que en el estómago las disoluciones son ácidas, para que con ello acepten que se pueden ingerir sustancias ácidas, porque, si observamos las respuestas dadas en las opciones anteriores, no todos los alumnos se referían al daño que los ácidos podían realizar en el estómago, sino que la mayoría indicaba que sería perjudicial para la garganta y otros órganos.

Las respuestas más correctas, a nuestro parecer, son las que hacen referencia al $\mathrm{pH}$ de algunos alimentos como limón, vinagre o refrescos de naturaleza ácida y que los bebemos sin ningún perjuicio para nuestro organismo. Este tipo de respuestas sí muestra que los alumnos aceptan la ingestión de sustancias ácidas, aplicando correctamente sus conocimientos sobre los ácidos y las bases a los fenómenos cotidianos.

Barral y otros (1981) han realizado una propuesta de experiencias sencillas basadas en la clasificación, utilizando papel indicador universal, de disoluciones acuosas y otras sustancias de uso doméstico. Paris (1989) profundiza al investigar sobre cómo construyen los alumnos de secundaria los conceptos de ácido y de base y cuál es el proceso evolutivo de su pensamiento desde la diferenciación empírica de las propiedades hasta la adquisición del concepto desde un punto de vista atómico-molecular.

Con respecto a las representaciones sociales (Solomon, 1987) que citamos en la introducción, podríamos añadir de nuestra propia experiencia que el hecho de mencionar el pH y su valor, incluso con independencia de éste, puede ser considerado por sí solo una buena cualidad del producto: hemos oído decir que es un champú mиy bueno, tiene hasta $\mathrm{pH}$.

Ideas que surgen de los anuncios publicitarios relacionadas con los ácidos, las bases, el pH y la neutralización

En este apartado desarrollaremos la investigación complementaria centrada en el análisis de los mensajes publicitarios emitidos en televisión. Para ello, describiremos siete mensajes publicitarios en los que encontramos referencias al $\mathrm{pH}$, la neutralización y la fuerza de los ácidos y pondremos especial atención sobre algunas ideas que se deducen de ellos. Dichos mensajes corresponden a los siguientes productos: lavavajillas Mistol (pH 5,5), de Henkel; Fairy Ultra y la lejía $A C E$, de Procter \& Gambel; champú y desodorante Johnson (pH 5,5), de Johnson \& Johnson; goma de mascar Happydent, distribuida por Perfetti, SA, y Orbit para niños de Wrigley.

1) Mistol ( $\mathrm{pH} 5,5)$ : En esta campaña publicitaria (ofrecida en televisión) se insiste en la idea de que el lavavajillas respeta las manos porque tiene el pH de la piel. Destacan dos cualidades, por un lado es concentrado y se come la grasa y, por otro lado, mientras otros concentrados tienen pH más elevados, el nuevo Mistol tiene el $p H=5,5$, dejando las manos perfectas, como si nada.
En este texto se afirma, de forma connotativa, que el producto es ácido y subyace la idea de que, al ser su pH igual al de la piel, parece como si no hiciera nada (manos perfectas como si nada). Esta misma idea surge de las imágenes que se observan en el anuncio del papel indicador dentro de dos recipientes, uno con Mistol y el otro con otros lavavajillas. En estas imágenes se ve cómo el papel indicador que se sumerge en el vaso del Mistol permanece inalterado (la parte mojada tiene igual color [verde] que la seca y que la disolución de Mistol), mientras que el indicador que se sumerge en el vaso de los «otros lavavajillas» aparece de color rojo una vez mojado. No hemos encontrado en la bibliografía ningún indicador que vire a verde para valores del $\mathrm{pH}<7$ o a rojo en valores del $\mathrm{pH}>7$, como se indica en la imagen. También hay que destacar que, mientras se cita el texto, se muestra en las imágenes de forma muy visible la etiqueta del envase en la que aparece un mensaje destacado: neutro para tus manos. Aunque en ningún momento se explicita que el $\mathrm{pH}=5,5$ corresponda al $« \mathrm{pH}$ neutro», sin embargo, subyace la idea de que este valor es el que corresponde a las disoluciones neutras así como que lo neutro es inocuo o también que no reacciona.

2) Compitiendo con este producto, de forma similar, se presenta el Fairy-Ultra, de Procter \& Gambel, con la cualidad de poseer un $\mathrm{pH}$ neutro y respeta las manos.

3) Champú Johnson's pH 5,5: En la publicidad televisiva de este producto se contrastan algunas cualidades beneficiosas del champú para el cabello frente a las perjudiciales que producen los demás champús. Entre las beneficiosas se cita brillo, fuerza, elasticidad y pelo sano; de forma contraria, muchos champús prometen brillo pero el pelo está débil. Para conseguir que el pelo recobre toda su fuerza y elasticidad se necesita $p H$ natural y las vitaminas del complejo fortalecedor de los champús Johnson's pH 5,5. En primer lugar, se está identificando un valor del $\mathrm{pH}=5,5$ con $\mathrm{pH}$ natural. Aunque sea el valor del $\mathrm{pH}$ de la piel no significa que el champú sea natural. En segundo lugar, se identifica ese valor del $\mathrm{pH}$ con la fuerza que proporciona al cabello.

4) Desodorante Johnson's pH 5,5: En este anuncio, también televisivo, se presenta el producto con la cualidad de poseer un valor del $\mathrm{pH}=5,5$ (todos somos $\mathrm{pH} 5,5$ ), que es el pH de la piel sana, con lo que, si se usa Johnson's pH 5,5, se tiene una piel fresca y sin irritación. De forma contraria, en la imagen del anuncio se observa que los demás desodorantes tienen un valor del $p H=8,4$ y este factor es el que produce la irritación de la piel.

5) Lejía $A C E$ : La cualidad principal destacada en la publicidad televisiva de este producto hace referencia a las disoluciones reguladoras por medio de la expresión control de acidez. Mediante el sonido del anuncio se explica que las lejías «normales» crean un ácido que puede dañar la ropa mientras que ACE mantiene el nivel de acidez adecuado y conserva las fibras fuertes $y$ blancas más tiempo; se sugiere, por tanto, que la lejía es ácida y se destaca que, para la ropa, «ácido» es igual a «dañino», idea que aparece en diversas campañas publicitarias. Hay que recordar que otra marca de lejía parece 
indicarnos con su nombre su carácter neutro (Neutrex de Henkel).

6) Happydent xylit (publicidad televisiva): Al comer, el pH de la boca disminuye provocando el riesgo de caries [...] De esta idea puede inferirse que los alimentos son ácidos y que éstos son perjudiciales para los dientes. En algunos anuncios se continúa con la siguiente afirmación: Happydent los neutraliza [los ácidos], restablece el pH y da frescor. Esta afirmación parece indicar que se produce una reacción de neutralización entre los ácidos de los alimentos y la goma de mascar, obteniéndose un $\mathrm{pH}$ final de 7. En el anuncio, el sonido se acompaña de unas imágenes que muestran la evolución del $\mathrm{pH}$ en el tiempo, con una progresión muy drástica del $\mathrm{pH}$, el cual primero desciende bruscamente para subir cuando se consume el producto en cuestión.

7) La marca Wrigley promociona su goma de mascar Orbit para niños con un anuncio muy similar al anterior, en el que también se utiliza el pH como cualidad beneficiosa y, por tanto, aconsejable para los dientes de los niños (recordamos la representación social que señalamos en párrafos anteriores: es un [...] muy bueno porque tiene hasta $\mathrm{pH}$ ).

\section{RELACIÓN ENTRE LAS IDEAS QUE SUR- GEN DE LOS ANUNCIOS Y LAS IDEAS DEL ALUMNADO}

La tabla I muestra un resumen de las ideas aparecidas en la publicidad en relación con el $\mathrm{pH}$ y la neutralización y que también manejan los alumnos en una proporción elevada. Los espacios en blanco muestran cómo, lógicamente, en ocasiones no hay relación entre algunas concepciones expresadas por los alumnos y la publicidad.

\section{ACTIVIDADES PARA EL TRABAJO EN EL AULA}

El estudio empírico centrado en el diagnóstico de las ideas que manifiestan los mensajes publicitarios y de las concepciones de los alumnos universitarios tiene por objeto buscar unas bases que nos permitan fundamentar las actividades que desarrollaremos en el aula de secundaria.

Un objetivo de la educación secundaria obligatoria es que «los alumnos seleccionen, contrasten y evalúen las informaciones procedentes de fuentes diversas» (MEC, 1991) y no cabe duda de que la televisión es una de las fuentes de información con más peso. Se estima que, por término medio, los jóvenes pasan ante el televisor unas 28 horas semanales durante el año (Gervilla, 1993), mientras que pasan en el aula unas 25 horas semanales durante el curso académico.

La enseñanza tradicional de los conceptos a los que hemos hecho referencia ( $\mathrm{pH}$ y neutralización) puede dar lugar a que los alumnos de los niveles señalados (secundaria y universidad) manejen las ideas comentadas en párrafos anteriores. No es muy habitual que en la clase de ciencias se utilice la publicidad para introducir o estudiar un cierto concepto científico. Las propuestas educativas que han puesto en contacto estos dos campos versan principalmente sobre temas de salud y consumo (Morón, 1995) o bien se centran en temas de actualidad medioambiental (Muriel, 1994).

Como se ha puesto de manifiesto en la sección anterior, hay numerosas promociones publicitarias que presentan conceptos sobre el $\mathrm{pH}$, los ácidos y las bases y otros temas ligados a ellos. Creemos que estas promociones pueden aprovecharse como instrumento didáctico y curricular en el contexto de un modelo constructivista de enseñanza. Este modelo, de acuerdo con Driver (1988), puede esquematizarse en cuatro etapas: $a$ ) una fase inicial de orientación para despertar el interés de los alumnos por el tema; $b$ ) una fase de explicitación en la que una tarea, adecuadamente elegida, permite que los alumnos discutan sobre sus propias ideas; $c$ ) una fase de restructuración en la que se utilizan estrategias para el cambio de las ideas previas por las que se admiten en la comunidad científica y, por último; $d$ ) una fase de aplicación y revisión de las ideas. Como señala Pozo (1996), esta última fase no debe consistir en abandonar las ideas con las que los alumnos llegan al aula sino reconstruir ideas más cercanas al conocimiento científico al integrar en dicho conocimiento las ideas cotidianas «asumiendo que se corresponden con diversos niveles de análisis».

Este modelo de enseñanza debe estar de acuerdo con los objetivos que se persiguen, con las características de los alumnos y del contexto en que se realiza el proceso de enseñanza.

En relación con los objetivos de conocimiento, ligados a la enseñanza de la química, nuestra propuesta sirve para presentar los conceptos del $\mathrm{pH}$ y de la neutralización a alumnos del segundo ciclo de la educación secundaria. Según la propuesta de De Manuel (1997), estos alumnos ya conocen lo que son las sustancias ácidas y básicas, así como algunas de sus propiedades (se desarrollan en primaria) y, en el primer ciclo de secundaria, se les puede presentar la escala del $\mathrm{pH}$ como grado de acidez o basicidad.

Por sus características de desarrollo psicológico, los alumnos a los que se dirige nuestra propuesta se sitúan en el nivel inicial y medio de las operaciones formales que, según las taxonomías de Shayer y Adey (1986), «tienen en cuenta más de un aspecto simultáneamente» a la hora de interpretar pasajes descriptivos. En cuanto al control de variables, «ven la necesidad de cambiar un factor cada vez [aunque] no controlan factores que no son perceptivamente obvios. También en este nivel «se comienza a observar la razón entre los casos que confirman y los que no confirman una relación determinada». Estas características son necesarias para que los alumnos obtengan el mayor rendimiento de las actividades propuestas, ya que en ellas se precisa la observación de los anuncios (texto, gráficos, etc.), la búsqueda de las seme- 
Tabla I

Neutralización y pH. Concepciones de los alumnos e ideas publicitarias.

\begin{tabular}{|c|c|c|c|}
\hline Concepciones de los alumnos & Nivel educativo & Ideas publicitarias & Producto \\
\hline $\begin{array}{l}\text { Afirman que toda reacción estequiométrica } \\
\text { produce una disolución neutra ( } \mathrm{pH}=7) \\
\text { independientemente de las fuerzas relativas } \\
\text { de los ácidos y de las bases que intervengan. } \\
\text { Identifican el proceso ácido-base con el proceso } \\
\text { de neutralización. }\end{array}$ & $\begin{array}{l}\text { Secundaria } \\
\text { y } 1^{\text {er }} \text { curso } \\
\text { de química } \\
\text { general. }\end{array}$ & $\begin{array}{l}\text { Los ácidos de los alimentos } \\
(\mathrm{pH}<7) \text { reaccionan con la } \\
\text { goma de mascar neutra- } \\
\text { lizándose }(\mathrm{pH}=7) \text {. }\end{array}$ & Happydent Xylit. \\
\hline $\begin{array}{l}\text { Tienen dificultades a la hora de clasificar como } \\
\text { ácido o como base algunos productos comunes } \\
\text { (café, leche, lejía, etc.). } \\
\text { No manejan una escala de acidez en productos } \\
\text { habituales. }\end{array}$ & $\begin{array}{l}\text { Todos los niveles, } \\
\text { especialmente los } \\
\text { alumnos de } 1^{\circ} \text { y } 2^{\circ} \\
\text { de lic. químicas. }\end{array}$ & La lejía es ácida ( $\mathrm{pH}<7)$. & Lejía $A C E$. \\
\hline $\begin{array}{l}\text { Relacionan el pH únicamente con la fuerza } \\
\text { o con la concentración. } \\
\text { Identifican fuerza de los ácidos y de las bases } \\
\text { con «daño» y con «dolor». } \\
\text { Relacionan ácidos fuertes con } \mathrm{pH} \ll<7 \\
\text { y bases fuertes con valores del } \mathrm{pH} \gg>7 \text {. }\end{array}$ & $\begin{array}{l}\text { Secundaria } \\
\text { y alumnos } \\
\text { de } 1^{\circ} \text { a } 5^{\circ} \\
\text { de universidad. }\end{array}$ & $\begin{array}{l}\text { Los ácidos dañan la ropa. } \\
\text { Los ácidos dañan los dientes. } \\
\text { El pH }=5,5 \text { da brillo, elasticidad } \\
\text { y fuerza al cabello. } \\
\text { El pH = 5,5 deja la piel sana, } \\
\text { fresca y no la irrita. }\end{array}$ & $\begin{array}{l}\text { Lejía } A C E \text {. } \\
\text { Happydent Xylit. } \\
\text { Orbit para niños. } \\
\text { Champú Johnson's } \\
\text { pH 5,5 } \\
\text { Desodorante } \\
\text { Johnson's pH 5,5. }\end{array}$ \\
\hline $\begin{array}{l}\text { Consideran que la ingestión de ácidos } \\
\text { es necesaria para que no afecte a la piel. } \\
\text { Consideran Neutro = Inocuo (no dañino). } \\
\text { El } 44 \% \text { considera que sería peligroso beber } \\
\text { disoluciones con pH < } 6 \text { o pH > } 8 \text {. } \\
\text { El } 24 \% \text { cree que sólo se pueden beber, sin peligro } \\
\text { para el organismo, disoluciones con un valor } \\
\text { del pH = 7. Sólo el } 7 \% \text { de los alumnos bebería } \\
\text { sustancias ácidas con valores del pH }<<7 \\
\text { (p.e. pH }=2,5 \text { ). }\end{array}$ & $\begin{array}{l}\text { Alumnos } \\
\text { de } 1^{\circ} \text { a } 5^{\circ} \\
\text { de universidad. }\end{array}$ & $\begin{array}{l}p H=5,5 \text { es el } p H \text { «neutro» para } \\
\text { la piel. } \\
\text { Neutro significa inocuo. }\end{array}$ & $\begin{array}{l}\text { Mistol pH 5,5 } \\
\text { Fairy-Ultra } \\
\text { Johnson's pH 5,5 }\end{array}$ \\
\hline $\begin{array}{l}\text { Relacionan el pH con la intensidad de la reacción } \\
\text { química. } \\
\text { Identifican neutro = no reacciona ni con ácidos } \\
\text { ni con bases en cualquier circunstancia. }\end{array}$ & $\begin{array}{l}\text { Secundaria } \\
\text { y alumnos } \\
\text { de } 1^{\circ} \text { a } 5^{\circ} \\
\text { de universidad. }\end{array}$ & $\begin{array}{l}\text { Neutro significa inerte } \\
\text { (no reacciona). } \\
\text { pH =5,5 es el } p H \text { «eutro» } \\
\text { para la piel. } \\
\text { Dos sustancias con valores } \\
\text { del pH iguales no reaccionan. }\end{array}$ & $\begin{array}{l}\text { Happydent Xylit. } \\
\text { Mistol pH 5,5. } \\
\text { Johnson's pH 5,5. }\end{array}$ \\
\hline & & pH 5,5 es el pH «natural». & Johnson's pH 5,5. \\
\hline
\end{tabular}

janzas que los relacionan entre sí y con los conceptos del $\mathrm{pH}$ y de la neutralización, la capacidad para el debate y el análisis.

Con respecto al contexto actual de la enseñanza de las ciencias, la propuesta de trabajo presentada pretende conectar conceptos científicos con fenómenos cotidianos a través de un medio muy presente en el mundo de los alumnos como es la publicidad. Se podrá con ello, por un lado, profundizar en conceptos estudiados con anterioridad y, por otro, trabajar con los mensajes publicitarios. Respecto a esta segunda cuestión creemos oportuno resaltar que su uso en las disciplinas de ciencias también puede, además de acercar los contenidos a los intereses del alumnado, ayudar a su interpretación y comprensión profunda, desarrollando la capacidad de crítica y análisis de la publicidad.

\section{Secuencia de actividades que se pueden aplicar en el aula}

Cabero (1998), Aparici y García Matilla (1987) y otros autores señalan diversos principios generales en la lectura de imágenes publicitarias. Para nuestro interés particular podemos presentar la siguiente secuencia de trabajo:

1) Se ven todos los anuncios que hemos señalado para que los alumnos puedan examinar qué poseen en común todos ellos. Se debe comenzar por los documentos con niveles de iconicidad elevada (abstracción baja). Igualmente es preferible trabajar primero con imágenes fijas $\mathrm{y}$ posteriormente presentar ejemplos en movimiento (casi todos los productos se promocionan tanto en soportes de prensa como en televisión). 
2) Los alumnos deben anotar pormenorizadamente las referencias al $\mathrm{pH}$ y a la neutralización que se hagan en cada anuncio, analizando el lenguaje publicitario desde el punto de vista denotativo, es decir, los elementos objetivos que contienen tanto el sonido como las imágenes (gráficos, imágenes de experiencias, etc.).

3) Estas anotaciones servirán para establecer posteriormente un debate y análisis que se centrará en las ideas que destacamos en párrafos anteriores y que les mostrarán algunas de sus propias concepciones. Este análisis es el más importante porque, en el debate, los alumnos podrán poner de manifiesto los elementos subjetivos (connotativos) que expresan los mensajes publicitarios y serán conscientes de algunas concepciones erróneas que manejan.

4) En cuarto lugar, se podría desarrollar una clasificación de productos comerciales, según los valores aproximados del $\mathrm{pH}$, utilizando papel indicador universal (indicador 1) y con otro indicador de fabricación propia, por ejemplo, una disolución acuosa de col lombarda (indicador 2) (Barral et al., 1981). Esta actividad se puede ampliar con otros productos similares que pueden encontrar en casa y que probablemente sean más baratos.

Se podría construir una tabla en la que se hiciera constar, además de los colores que toman los dos indicadores, el valor aproximado del $\mathrm{pH}$ del producto así como si en el envase $o$ en el anuncio publicitario se utiliza como cualidad de dichos productos. En caso afirmativo se escribirá en el recuadro correspondiente lo que aparezca, tanto en el anuncio como en el envase. La tabla podría presentarse como se indica a continuación (Tabla II).

La secuencia que acabamos de proponer describe de forma general lo que se puede desarrollar en el aula. De forma particular, en cada anuncio se pueden concretar algunas actividades específicas, como se expone a continuación.

\section{Lavavajillas Mistol ( $\mathrm{pH}$ 5,5)}

- Se comprobará con los alumnos el valor del pH de este producto. También se buscará el $\mathrm{pH}$ de otros lavavajillas $\mathrm{y}$ detergentes en los que no se especifique su $\mathrm{pH}$.
- Para diferenciar entre sustancia neutra y sustancia inerte, se puede preparar una disolución neutra de $\mathrm{NaCl}$ y añadirle una disolución neutra de $\mathrm{AgNO}_{3}$, obteniéndose, el siguiente equilibrio: $\mathrm{NaCl}+\mathrm{AgNO}_{3} \rightleftarrows \mathrm{NaNO}_{3}+$ $\mathrm{AgCl} \downarrow$ y observando la formación de un precipitado (dos disoluciones neutras han reaccionado).

- En el anuncio se observa el efecto de dos disoluciones acuosas (una de Mistol y la otra de «otros lavavajillas») sobre un indicador amarillo-verdoso. Esta imagen se puede comentar con los alumnos después de que éstos lleven a cabo la clasificación de ciertos productos entre ellos varios lavavajillas. Esta clasificación se va a llevar a cabo con papel indicador universal (muy similar en forma y color al del anuncio). Se podría aprovechar para introducir los conceptos macroscópicos relacionados con los indicadores y comparar varios indicadores tanto en papel como en disolución.

\section{Champú Johnson's (pH 5,5)}

- Se puede debatir con los alumnos lo que significa el término natural y discutir si el $\mathrm{pH}$ 5,5 de este producto puede considerarse como el «pH natural», según se afirma en su publicidad.

- Se comprobará si la idea que se comenta en el anuncio publicitario, acerca de la identificación del valor del $\mathrm{pH}$ con la fuerza que le proporciona al cabello, puede llevar a los alumnos a pensar que los ácidos son fuertes, idea que manejan los alumnos universitarios, según hemos detectado (Jiménez, 2000).

\section{Lejía $A C E$}

- En la publicidad de este producto se destaca la cualidad de poseer control de acidez. Este aspecto, relacionado con las disoluciones reguladoras, no debería tratarse, con excesiva profundidad, con los alumnos de segundo ciclo de secundaria, puesto que consideramos que debe estudiarse en niveles superiores. La dificultad de esos conceptos ha sido comprobada en varios ítems de la prueba diseñada para alumnos universitarios. A modo de ejemplo, el $22 \%$ de los alumnos universitarios diagnosticados considera que las disoluciones tampón de dos sustancias siempre dan el mismo $\mathrm{pH}$ independientemen-

\begin{tabular}{|c|c|c|c|c|c|}
\hline Producto & Color del indicador 1 & Color del indicador 2 & Valor del pH & Anuncio en televisión & Envase \\
\hline $\begin{array}{c}\text { Mistol } \\
(p H=5,5)\end{array}$ & & & & $\begin{array}{c}p H=5, \text { S. Respeta tu piel. } \\
\text { Tus manos como si nada. }\end{array}$ & $\begin{array}{c}\text { Neutro } \\
\text { para la piel. }\end{array}$ \\
\hline & & & & \\
\hline
\end{tabular}


Tabla III

Objetivos y conceptos que se plantean para cada actividad.

\begin{tabular}{|c|c|c|}
\hline Objetivos & Conceptos & Actividades \\
\hline $\begin{array}{l}\text { Comparar la información que aportan los } \\
\text { mensajes publicitarios con los que manejan } \\
\text { los científicos. Considerar el carácter mate- } \\
\text { mático de la escala del pH. }\end{array}$ & $\begin{array}{l}\text { La escala del } \mathrm{pH} \text { es una medida del grado } \\
\text { de acidez (o basicidad) de cualquier pro- } \\
\text { ducto. No existe un sólo «pH natural». }\end{array}$ & $\begin{array}{l}\text { Clasificación, según su pH, de los productos } \\
\text { que aparecen en la publicidad (lavavajillas, } \\
\text { detergentes, champús, lejías, etc.) y de otros en } \\
\text { los que no se especifique su pH ni en su envase } \\
\text { ni en su publicidad. } \\
\text { Clasificación, según su pH, de productos natu- } \\
\text { rales como algunos alimentos (zumo de limón, } \\
\text { agua potable, saliva, orina, etc.). }\end{array}$ \\
\hline $\begin{array}{l}\text { Distinguir entre neutralización y reacción } \\
\text { estequiométrica. }\end{array}$ & $\begin{array}{l}\text { Neutralización equivale a una reacción } \\
\text { que conduzca a una disolución cuyo valor } \\
\text { final del } \mathrm{pH}=7 \text {. Para que una base neutra- } \\
\text { lice un ácido, hay que tener en cuenta las } \\
\text { cantidades necesarias y las fuerzas de los } \\
\text { ácidos y de las bases implicadas des- } \\
\text { echando la idea de que todos las bases (en } \\
\text { cualquier cantidad) neutralizan los áci- } \\
\text { dos de la boca (Happydent). }\end{array}$ & $\begin{array}{l}\text { Comprobar el pH de una disolución obtenida a } \\
\text { partir de } n \text { moles de ácido fuerte y } n \text { moles de } \\
\text { base débil o viceversa. }\end{array}$ \\
\hline $\begin{array}{l}\text { Diferenciar entre sustancia neutra y sustan- } \\
\text { cia inocua. }\end{array}$ & $\begin{array}{l}\text { Hay sustancias (incluso alimentos) que } \\
\text { no ofrecen peligro para el organismo a } \\
\text { pesar de no ser neutras. }\end{array}$ & $\begin{array}{l}\text { Comprobar el } \mathrm{pH} \text { de algunas sustancias que no } \\
\text { sean neutras (zumos, refrescos, vinagre, diso- } \\
\text { lución de aspirina, de } \mathrm{NaHCO}_{3} \text { ) y que no son } \\
\text { perjudiciales para el organismo. }\end{array}$ \\
\hline $\begin{array}{l}\text { Comprobar que «ácido» no es igual a } \\
\text { «dañino». }\end{array}$ & Los alimentos son ácidos. & $\begin{array}{l}\text { Observar el } \mathrm{pH} \text { de algunos alimentos y reforzar } \\
\text { la idea de que el } \mathrm{pH} \text { no determina el perjucio (o } \\
\text { el beneficio) que puedan hacer sobre el orga- } \\
\text { nismo. }\end{array}$ \\
\hline $\begin{array}{l}\text { Diferenciar entre sustancia neutra y sustan- } \\
\text { cia inerte. }\end{array}$ & $\begin{array}{l}\text { El equilibrio entre las especies químicas } \\
\text { se da cualquiera que sea la cantidad o la } \\
\text { proporción en la que se encuentra una de } \\
\text { ellas. El pH depende de todos los equili- } \\
\text { brios existentes en la disolución acuosa. }\end{array}$ & $\begin{array}{l}\text { Preparar una disolución neutra de } \mathrm{NaCl} \text { y com- } \\
\text { probar su pH por medio del papel indicador } \\
\text { universal. Añadirle otra disolución de } \mathrm{AgNO}_{3} \\
\text { y observar la formación de un precipitado. }\end{array}$ \\
\hline $\begin{array}{l}\text { Desarrollar el sentido crítico a la hora de } \\
\text { recibir los mensajes que provienen de las } \\
\text { imágenes publicitarias. } \\
\text { Comparar los virajes de diferentes indicado- } \\
\text { res y los valores del pH en los que viran. }\end{array}$ & $\begin{array}{l}\text { El papel indicador universal no es el úni- } \\
\text { co papel indicador. No todos los indica- } \\
\text { dores tienen los mismos colores. } \\
\text { Los indicadores tienen un intervalo de } \\
\text { viraje que depende de la naturaleza del } \\
\text { indicador. }\end{array}$ & $\begin{array}{l}\text { Manejar diferentes indicadores, entre ellos un } \\
\text { papel indicador de fabricación propia. } \\
\text { Buscar una clasificación de indicadores y ver } \\
\text { si alguno vira de verde a rojo en la zona básica } \\
\text { del pH. }\end{array}$ \\
\hline $\begin{array}{l}\text { Tratar, al nivel macroscópico, el efecto regu- } \\
\text { lador de ciertas disoluciones. }\end{array}$ & $\begin{array}{l}\text { La acción reguladora de una disolución } \\
\text { tampón es efectiva siempre que no se le } \\
\text { añadan cantidades excesivas de ácidos o } \\
\text { de bases. } \\
\text { El «control de acidez» al que hace refe- } \\
\text { rencia la publicidad de la lejía ACE es } \\
\text { propio de una disolución tampón. }\end{array}$ & $\begin{array}{l}\text { Preparar una disolución tampón y comprobar } \\
\text { que, si se añaden pequeñas cantidades de áci- } \\
\text { dos o de bases (aunque sean fuertes o estén } \\
\text { concentrados), su pH permanece constante (el } \\
\text { color del indicador no varía). } \\
\text { Añadir las mismas cantidades de ácidos o de } \\
\text { bases del epígrafe anterior sobre una disolu- } \\
\text { ción que no sea reguladora (por ejemplo, sobre } \\
\text { un volumen determinado de agua destilada o } \\
\text { de una disolución de } \mathrm{NaCl} \text { y y comprobar que } \\
\text { en dicha disolución varía considerablemente } \\
\text { su pH. } \\
\text { Comprobar si la lejía } A C E \text { es una disolución } \\
\text { reguladora, añadiendo pequeñas cantidades de } \\
\text { ácidos o bases (fuertes y concentradas). }\end{array}$ \\
\hline
\end{tabular}

te de las concentraciones de las sustancias que la integran; otro $21 \%$ afirma que sólo se forman las disoluciones reguladoras si los iones que la componen se encuentran en proporciones equimolares.
Sin embargo, como en el anuncio se alude al control de acidez, podemos introducir el concepto de disolución reguladora al nivel macroscópico, es decir, por medio de la variación del color de los indicadores (fenómeno 
observable). Podemos comprobar que hay disoluciones que regulan el $\mathrm{pH}$ mientras no se añadan cantidades excesivas de ácidos o de bases; por ejemplo, una disolución formada por una mezcla de sales que contengan los

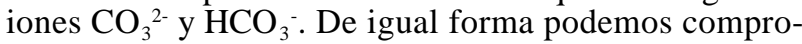
bar si la lejía $A C E$ es una disolución de este tipo.

- La frase que se cita en el anuncio (las lejías «normales» crean un ácido) parece indicar que las lejías son ácidas. Se debe comprobar con los alumnos el valor del pH de ésta y de otras lejías.

- Se podría comprobar con los alumnos cuál es el pH de algunas bebidas (alimentos, en general) para verificar que no son dañinos (sino beneficiosos para el ser humano) aunque sean ácidos con valores del $\mathrm{pH}=2,5$ (en el caso de los refrescos). Con esta actividad se pretende debatir sobre la relación que se establece en el anuncio entre «ácido = dañino».

\section{Goma de mascar Happydent xilit}

- Se puede comentar con los alumnos si los alimentos son ácidos y si son perjudiciales para los dientes. Tras observar el anuncio de este producto, se puede plantear

Figura 1

Los conocimientos científicos: papel de la enseñanza formal e informal.

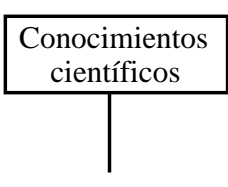

Usados por sistemas de enseñanzas sin conexión

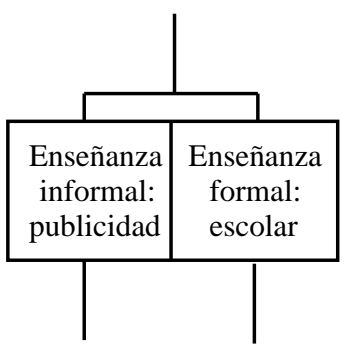

Producen en los alumnos

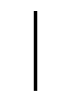

Pseudosaberes o aprendizajes poco significativos en el aula los siguientes interrogantes: ¿Qué valor del pH tiene la saliva? ¿Por qué son perjudiciales los ácidos para los dientes? ¿Los ácidos son siempre perjudiciales? ¿Acaso no hay alimentos ácidos?

- Proponemos pedir a los alumnos que comprueben el valor del $\mathrm{pH}$ de su saliva antes y después de comer algún alimento o cuando mascan chicle. Para ello basta con depositar algunas gotas de saliva sobre una cápsula de Petri y utilizar papel universal.

- Podemos centrar la atención de los alumnos sobre la gráfica $\mathrm{pH}$ versus tiempo que aparece en el anuncio para destacar que el proceso no es tan drástico, como se muestra en los valores del $\mathrm{pH}$ antes y después de comer y de mascar Happydent.

Las actividades concretas que hemos descrito en este apartado, junto con los objetivos que se pretenden conseguir con cada una de ellas y los conceptos a los que hacen referencia, han sido resumidos en la tabla III. Los objetivos que pueden perseguirse con el uso de la publicidad en el aula, en la enseñanza, están relacionados con el aumento de la capacidad de resolver problemas y con la toma de decisiones, sobre todo en la vida cotidiana, potenciándose una actitud crítica ante la publicidad y las cualidades beneficiosas que en ellas se destacan. Por otro lado, en dicha tabla incluimos otras actividades complementarias experimentales que sirven para comparar las ideas que manejan los alumnos (presentes también en la publicidad) con las ideas científicas.

\section{CONCLUSIONES}

Hemos puesto de manifiesto las coincidencias que en numerosos casos se aprecian entre las concepciones de los alumnos sobre procesos ácido-base y los mensajes publicitarios que utilizan estos conceptos. El lenguaje publicitario se apropia, para sus fines, de numerosos términos provenientes de diversas ramas de las ciencias (ejemplos muy actuales son los liposomas, bactericidas, o microgel); en otros casos, los vulgariza y degrada (colesterol bueno, energía azul, molécula devoragrasa).

Dada la redundancia publicitaria, y aceptando la complejidad de estos fenómenos, es muy probable que sus mensajes coadyuven en la creación de lo que Giordan denomina un pseudosaber (Giordan y De Vecchi, 1988); es decir, palabras o términos con connotaciones subjetivas de eficacia, palabras que se poseen en la memoria pero sin actividad funcional alguna. Igualmente el alumno repite algunas veces las palabras de un texto o unos apuntes que no le dicen nada más allá de su necesidad de memorizar para el examen.

Así mismo, con respecto a los conceptos del pH y de la neutralización, hemos destacado la relación entre el pH $\mathrm{y}$ algunos conceptos biológicos en los que no hemos profundizado. Sería interesante que buscáramos las ideas que manejan los alumnos acerca de ese tema. 
Consideramos que el desconocimiento de los alumnos sobre la naturaleza ácida o básica de productos muy comunes en el hogar puede ser, en cierta medida, solventada con el uso de la publicidad como excusa para introducir su estudio en las aulas de ciencias. La propuesta presentada pretende servir de base y motivación en la búsqueda de conexiones útiles entre el mundo de la ciencia y las concepciones de los alumnos y la terminología científica publicitaria (Fig. 1).

Parece obvio que el aula, en sus niveles obligatorios, tiene que utilizar e integrar en su currículo la formación en los medios y además utilizarlos como elementos formativos y de aprendizaje, de modo que se produzca una relación verdadera entre escuela y sociedad, que escuela y sociedad no sean mundos completamente separados. El uso de la publicidad como herramienta didáctica puede ser, entre otros, un puente entre ambos sistemas.

\section{NOTA}

Direcciones de interés donde pueden solicitarse los anuncios comentados:

Henkel Ibérica: Oficina central, c/ Córcega, 480-492. Barcelona. (http://www.henkel.es)

Johnson\&Johnson España: Paseo de las Doce Estrellas, 5-7. Campo de las Naciones. 28042 Madrid. (http://www.jnj.com)

Distibuciones Perfetti, SA: Vilassar de Dalt (Barcelona).

Procter\&Gambel España: Avenida del Partenón, 16-18. Campo de las Naciones. 28042 Madrid. (http://www.pg.com)

Wrigley: (http://www.wrigley.com)

\section{REFERENCIAS BIBLIOGRÁFICAS}

APARICI, R. y GARCÍA MATILLA, E. (1987). Lecturas de imágenes. Madrid: De la Torre.

ARCONADA, M.A. (1994). Los consumidores de anuncios. Escola Crítica, 5, pp. 65-80.

BÁRCENAS, S., CALATAYUD, M.L. y FURIÓ, C. (1997). Dificultades en el aprendizaje y en la enseñanza de las reacciones ácido-base. Enseñanza de las Ciencias, núm. extra, pp. 167-168.

BARRAL, A., COROMINAS, J., GIL, A. e IZQUIERDO, M. (1981). Jugando con indicadores. Cuadernos de Pedagogía, 81(10), p. 72.

BORSESE, A. (1992). Fuerza de los ácidos y de las bases y criterios de cálculo del pH. Enseñanza de las Ciencias, 10(1), pp. 86-88.

CABERO, J. (1998). Publicidad y educación, educación y publicidad. Colección de Educación y Medios de Comunicación II. Huelva: Grupo Comunicar Eds., pp. 8-17.

CROS, D. et al. (1986). Conceptions of first year university students of the constitution of matter and the notions of acids and bases. European Journal of Science Education, 8(3), pp. 305-313.

CROS, D. et al. (1988). Conceptions of second year university students of some fundamental notions in Chemistry. International Journal of Science Education, 10(3), pp. 331-336.
DE LA GUARDIA, M., SALVADOR, A., LÓPEZ, J. y CARRIÓN, J.L. (1985). Errores conceptuales en la concepción de los equilibrios ácido-base. Enseñanza de las Ciencias, núm. extra, p. 61.

DE MANUEL, E. (1997). Aprendizaje de los conceptos de ácido y debase en los niveles educativos primario y secundario, en Jiménez, R. y Wamba, A.M.Avances en didácticas de las ciencias experimentales. Huelva: Servicio de Publicaciones de la Universidad de Huelva, pp. 207-214.

DE MANUEL, E., JIMÉNEZ, M.R. y SALINAS, F. (1998). Revisión bibliográfica sobre conceptos de los alumnos relacionados con los procesos ácido-base. Revista de Educación de la Universidad de Granada, 11, pp. 61-72.

DE MANUEL, E., JIMÉNEZ, M.R. y SALINAS, F. (1999). Conceptos relacionados con los ácidos y las bases al nivel macroscópico: evolución histórica e ideas de los alumnos, en Martínez Losada, C. y García Barros, S. La didáctica de las ciencias. Tendencias actuales. La Coruña: Servicio de Publicaciones de la Universidad de La Coruña, pp. 359-368.

DRIVER, R. (1988). Un enfoque constructivista para el desarrollo del currículo en ciencias. Enseñanza de las Ciencias, 6(2), pp. 109-120.

GERVILLA, E. (1993). Postmodernidad y educación. Valores y cultura de los jóvenes. Madrid: Dykinson.

GIORDAN, A. y DE VECCHI, G. (1988). Los orígenes del saber. Sevilla: Díada. 
JIMÉNEZ, M.R. (2000). «Contenidos relacionados con los procesos ácido-base: diagnóstico y propuestas al nivel universitario.» Tesis doctoral (no publicada). Universidad de Granada.

LUCAS, A. (1983). Scientific literary and informal learning. Studies in Science Education, 10, pp. 1-36.

MEC (1991). Real Decreto 1007/1991, de 14 de junio, por el que se establecen las enseñanzas mínimas correspondientes a la educación secundaria obligatoria. BOE, 152, anexo I. Madrid.

MEC (1992 a). Real Decreto 1178/1992, por el que se establecen las enseñanzas mínimas del bachillerato. BOE, 253. Madrid.

MEC (1992b). Real Decreto 1179/1992, por el que se establece el currículo del bachillerato. BOE, 253. Madrid.

MORÍN, E. (1984). Ciencia sin consciencia. Barcelona: Anthropos.

MORÓN, J.A. (1995). Educación para la salud: un reto para todos. Sevilla: Ayuntamiento de Dos Hermanas.

MUÑOZ, J. (1995). Contemos con la publicidad. Comunicar, 5, pp. 84-91.

MURIEL, S. (1994). Una aproximación a los suplementos de ciencias. Colección Prensa y Educación, IV, pp. 48-51. Sevilla: Grupo GIPDA.

NAKHLEH, M.B. y KRAJCIK, J.S. (1994). Influence of levels of information as presented by different technologies on students' understandings of acid, base and $\mathrm{pH}$ concepts. Journal of Research in Science Teaching, 31(10), pp. 10771096.

PARIS, M. (1989). Esquemas conceptuales en torno a los ácidos y las bases. Implicaciones de la instrucción en el proceso evolutivo de estos conceptos. Enseñanza de las Ciencias, núm. extra (III Congreso), tomo 2, pp. 290-293.

POZO, J.I. (1996). Las ideas del alumnado sobre la ciencia: de dónde vienen, adónde van... y mientras tanto qué hacemos con ellas. Alambique, 7, pp. 18-26.

POZO, J.I., GÓMEZ CRESPO, M.A., LIMÓN, M. y SANZ, A. (1990). Bases psicopedagógicas para la elaboración de un

[Artículo recibido en abril de 1999 y aceptado en julio de 2000.] currículo en ciencias: química. Madrid: Universidad Autónoma de Madrid. Facultad de Psicología.

POZO, J.I., SANZ, A., GÓMEZ CRESPO, M.A. y LIMÓN, M. (1991). Las ideas de de los alumnos sobre la ciencia: una interpretación desde la psicología cognitiva. Enseñanza de las Ciencias, 9, pp. 83-94.

POZO, J.I. (1996). Las ideas del alumnado sobre la ciencia: de dónde vienen, adónde van... y mientras tanto qué hacemos con ellas. Alambique, 7, pp. 18-26.

REAL ACADEMIA DE CIENCIAS EXACTAS, FÍSICAS Y NATURALES (1996). Vocabulario científico y técnico. Madrid: Espasa.

ROMÁN, P., BARROSO, J. y DOMENE, S. (1998). Bibliografía general sobre publicidad y educación. Colección de Educación y Medios de Comunicación, II, pp. 114-118. Huelva: Grupo Comunicar.

ROSS, B. y MUNBY, H. (1991). Concept mapping and misconceptions: a study of high-school students' understandings of acids and bases. International Journal of Science Education, 13(1), pp 11-23.

SHAYER, M. y ADEY, P. (1986). La ciencia de enseñar ciencias (desarrollo cognitivo y exigencias del currículo). Madrid: Narcea.

SOLOMON, J. (1987). Social influences on the construction of pupils' understanding of science. Studies in Science Education, 14 , pp. 63-82.

TAMIR, P. (1998). Assessment and evaluation in Science Education: Opportunities to Learn and Outcomes, en Fraser, B.J. y Tobin, K.G. International Handbook of Science Education, pp. 761-789. Dordercht: Kluwer A.P.

TRILLA, J. (1993). La educación en la escuela. Barcelona: Arial.

VIDYAPATI, T.J. y SEETHRAMAPPA, J. (1995). Higher secondary school student's concepts of acids and bases. School Science Review, 77(278), pp 82-84.

ZOLLER, U. (1990). Students' misunderstandings and misconceptions in college freshman chemistry (General and Organic). Journal of Research in Science Teaching, 27(10), pp. 1053-1065. 